\title{
Lanthanide Complexes of Some High Energetic Compounds (II), Crystal Structures and Thermal Properties of Picrate Complexes
}

\author{
Sock-Sung Yun, "Sung Kwon Kang, *Hong-Ryol Suh, Hyung-Sock Suh, \\ Eun Kwang Lee, Jae-Kyung Kim, ${ }^{\dagger}$ and Chong-Hyeak Kim ${ }^{\dagger}$ \\ Department of Chemistry, Chungnam National University, Daejeon 305-764, Korea. *E-mail: skkang@cnu.ac.kr \\ ${ }_{\dagger}^{\dagger}$ High Explosive Team, Agency for Defense Development, P.O. Box 35-5, Daejeon 305-600, Korea \\ ¿Chemical Analysis Laboratory, Korea Research Institute of Chemical Technology, P.O. Box 107, Daejeon 305-606, Korea \\ Received January 17, 2005
}

\begin{abstract}
The $\mathrm{Ln}(\mathrm{III})$ complexes with picrate ligand, $\left[\mathrm{Sm}(\mathrm{Pic})_{2}\left(\mathrm{H}_{2} \mathrm{O}\right)_{6}\right] \mathrm{Pic} \cdot 6 \mathrm{H}_{2} \mathrm{O}, \mathbf{1}$, and $\left[\mathrm{Ho}(\mathrm{Pic})\left(\mathrm{H}_{2} \mathrm{O}\right)_{7}\right](\mathrm{Pic})_{2} \cdot 3 \mathrm{H}_{2} \mathrm{O}, \mathbf{2}$, have been synthesized and their crystal structures are analyzed by X-ray diffraction methods. Complex 1, crystallizes in the monoclinic $P 2{ }_{1} / n$ space group and complex $\mathbf{2}$ in the triclinic $P-1$ space group. In complex $\mathbf{1}$, two picrate ligands coordinate to the $\mathrm{Sm}$ (III) ion, one of them in the bidentate fashion. There are one picrate anion and six water molecules in the crystal lattice. The nine-coordinated Sm(III) ion forms a slightly distorted tricapped trigonal prism. In complex $\mathbf{2}$, only one picrate ligand coordinates to the metal ion as a monodentate. There are two picrate anions and three water molecules in the crystal lattice. The eight-coordinated Ho(III) ion forms a distorted bicapped trigonal prism. Based on the results of the TG-DTG and DSC thermal analysis, it was analyzed that the lanthanide picrate complexes $\mathbf{1}$ and $\mathbf{2}$ are thermally decomposed in three distinctive stages, the dehydration, the picrate decomposition, and the formation of the metal oxide.
\end{abstract}

Key Words : Lanthanide complex, Picric acid, Thermal analysis, Crystal structure

\section{Introduction}

The nitrophenols and their metal salts as high energetic materials have been the subject of fairly extensive investigation in various aspects, such as the thermal and combustion properties, ${ }^{1-3}$ molecular structures, ${ }^{4-8}$ solvent extraction, ${ }^{9,10}$ and coordination behavior. ${ }^{11-13}$ The molecular structures of lanthanide complexes of 2,4,6-trinitrophenol (picric acid) have been thoroughly studied by Harrowfield et $a .^{6}$ In the picrato hydrates of lighter members of the lanthanide series ( $\mathrm{La} \rightarrow \mathrm{Tb}$ ), two picrate ligands are coordinated to the metal ion, one as monodentate and the other as being quasi-bidentate. ${ }^{6 a}$ On the other hand, one picrate is coordinated in monodentate fashion in the complexes of heavier lanthanide metal ions (Dy $\rightarrow \mathrm{Lu}$ ). ${ }^{6 \mathrm{~b}}$ However, unlikely with the picrato hydrates of earlier lanthanide, the picrate ligands in the samarium complex are both clearly unidentate. ${ }^{6 \mathrm{~d}}$

As the extension of the studies, we have investigated the X-ray single crystal structures of the samarium and holmium complexes of picric acid. The thermal properties of the neodymium, samarium, gadolinium, and holmium complexes of picric acid have been also investigated.

\section{Experimental Section}

Preparation of the complexes. The lanthanide ion solutions were prepared by dissolving respective lanthanide oxides ( $\mathrm{Ln}_{2} \mathrm{O}_{3}$, Aldrich; ca. $\left.4.8 \mathrm{mmol}\right)$ in distilled water $(20$ $\mathrm{mL}$ ) at $60{ }^{\circ} \mathrm{C}$ with stirring under the hot water bath, adjusting the $\mathrm{pH}$ of the solutions to $c a$. 2 with $7 \mathrm{M} \mathrm{HNO}_{3}$ solutions. The ligand solution was prepared by dissolving picric acid
$\left(\mathrm{C}_{6} \mathrm{H}_{3} \mathrm{~N}_{3} \mathrm{O}_{7}\right.$, Merk; $\left.13.75 \mathrm{~g}, 0.06 \mathrm{~mol}\right)$ in distilled water (55 $\mathrm{mL})$ at $60{ }^{\circ} \mathrm{C}$ with stirring under the water bath. The $\mathrm{pH}$ of the ligand solution was adjusted to about 6 with $3 \mathrm{M} \mathrm{LiOH}$ solution. The lanthanide metal solution was added dropwise slowly to the ligand solution. The volume of the mixture was reduced to $50 \mathrm{~mL}$ by evaporation of the solvent. The reaction mixture was stirred for 3 hours at $60^{\circ} \mathrm{C}$ adjusting its $\mathrm{pH}$ to about 4 and then filtrated through a plastic membrane of $0.45 \mu \mathrm{m}$ pore size in order to remove the small amount of the precipitate formed. The final solution was cooled and kept in the refrigerator. Light yellow crystals of the picrate complexes of respective lanthanide metal ions were obtained at room temperature over a period of a few weeks. The complexes were recrystalized from distilled water. Upon cooling of hot aqueous solutions of the picrate complexes to room temperature, crystals of the complexes suitable for single crystal X-ray diffraction were obtained. A decaying tendency without water at room temperature is observed for the crystals of the samarium picrate, indicating that the crystals are comparatively unstable in atmosphere. Thus the relatively large error range in the analytical data was observed for the Sm-picrate complex 1.

The contents of carbon, hydrogen, and nitrogen were determined by a CE EA-1110 elemental analyzer. Anal. Calcd. (\%) for $\mathrm{C}_{18} \mathrm{H}_{30} \mathrm{~N}_{9} \mathrm{O}_{33} \mathrm{Sm}$ : C, 20.55; H, 2.85; N, 11.99 . Found: C, 21.24; H, 2.31; N, 11.68. Anal. Calcd. (\%) for $\mathrm{C}_{18} \mathrm{H}_{26} \mathrm{~N}_{9} \mathrm{O}_{31} \mathrm{Ho}: \mathrm{C}, 20.98 ; \mathrm{H}, 2.53 ; \mathrm{N}, 12.24$. Found: $\mathrm{C}$, 21.00; H, 2.13; N, 12.27.

X-ray crystallography. The data for X-ray structure determination was collected on a Siemens P4 diffractometer equipped with graphite monochromated Mo $\mathrm{K} \alpha$ radiation $(\lambda$ $=0.71073 \AA)$ at $293 \mathrm{~K}$. The unit cell dimensions were 
determined on the basis of 40 reflections in the range of $5.9^{\circ}$ $<\theta<12.6^{\circ}$ and $4.7^{\circ}<\theta<12.5^{\circ}$ for Sm(III) and Ho(III) picrate, respectively. The data was collected by the $\omega-2 \theta$ technique. Empirical absorption correction was applied to the intensity data. The standard direct method was used to position the heavy atoms. The remaining non-hydrogen atoms were located from the subsequent difference Fourier synthesis. All non-hydrogen atoms were refined anisotropically. All hydrogen atoms were calculated in ideal positions and were riding on their respective carbon atoms $\left(B_{\text {iso }}=1.2 B_{\text {eq }}\right)$. The structure was refined in a full matrix least-squares calculation on $F^{2}$. Program used to solve structure and to refine structure; SHELXS97 and SHELXL97. ${ }^{14}$ Molecular graphics; Ortep-3 for windows. ${ }^{15}$

Thermal analysis. The thermal decomposition of the complex was investigated on a TGA 50 apparatus (MettlerToledo GmbH, Switzerland). The conditions of TG were: sample masses of $c a$. 1-2 mg being heated at the heating rate of $10{ }^{\circ} \mathrm{Cmin}^{-1}$ under a nitrogen atmosphere. The DSC experiments were carried out with a model $821^{\mathrm{e}}$ apparatus (Mettler-Toledo GmbH, Switzerland) fitted with a standard aluminum sample pan. The conditions of DSC were: sample masses of $\mathrm{ca} \mathrm{1-2} \mathrm{mg}$ being heated at the heating rate of 10 ${ }^{\circ} \mathrm{Cmin}^{-1}$ under the static air atmosphere. A sample of indium was used as the reference.

\section{Results and Discussion}

Crystal structure. Thus X-ray crystallographic data could be obtained by data collection with a single crystal sealed in quartz capillary under a microscope. The details of the crystallographic data for $\left[\mathrm{Sm}(\text { pic })_{2}\left(\mathrm{H}_{2} \mathrm{O}\right)_{6}\right] \cdot($ pic $) \cdot 6 \mathrm{H}_{2} \mathrm{O}, \mathbf{1}$ are given in Table 1. As a family member, unit cell data of samarium(III) picrate are closely related to the data for the other picrate complexes of lighter lanthanide(III) metal ions. ${ }^{6 \mathrm{a}}$ Unlikely with that reported, ${ }^{6 \mathrm{~d}}$ the samarium picrate complex appeared to be such a dodecahydrated complex like the members of lighter lanthanide series, whose stoichiometric chemical formula is $\mathrm{Ln}(\text { pic })_{3}\left(\mathrm{H}_{2} \mathrm{O}\right)_{12}$. It is comprising $\left[\mathrm{Sm}(\text { pic })_{2}\left(\mathrm{H}_{2} \mathrm{O}\right)_{6}\right]^{+}$cation, a picrate counter anion, and six water molecules in the outer coordination sphere.

The selected bond lengths and angles for complex $\mathbf{1}$ are listed in Table 2. An ORTEP diagram of the molecular structure for complex $\mathbf{1}$ is presented by labeling atoms in Figure 1. The structural feature of complex $\mathbf{1}$ is that two picrates and six water ligands are coordinated directly to the $\mathrm{Sm}$ atom in the inner coordination sphere forming the complex cation, while one picrate as a counter anion is bound to the complex cation. In addition, there are six water molecules (Ow1-Ow6) in the outer sphere. The Sm(III) ion is coordinated to nine $\mathrm{O}$ atoms. Six of these neighbors are the $\mathrm{O}$ atoms of water molecules (Ow7-Ow12). The Sm-O (O in water) bond distances are within the range of 2.443(5)2.512(6) $\AA$ and are slightly shorter or longer than the sum of the covalent radii of the Sm and O atoms (2.46 $\AA$ ).

The complex 1 has one chelate ring composed of a Sm(III) ion, $\mathrm{O} 1$ atom of the phenol group, and $\mathrm{O} 2$ atom of the nitro group of one picrate ligand. The $\mathrm{Sm}-\mathrm{O}$ distance to one of the

Table 1. Crystal data and structure refinement for $\left[\mathrm{Sm}(\mathrm{pic})_{2}\left(\mathrm{H}_{2} \mathrm{O}\right)_{6}\right] \cdot(\mathrm{pic}) \cdot 6 \mathrm{H}_{2} \mathrm{O}$ and $\left[\mathrm{Ho}(\mathrm{pic}) \cdot 7 \mathrm{H}_{2} \mathrm{O}\right] \cdot(\mathrm{pic})_{2} \cdot 3 \mathrm{H}_{2} \mathrm{O}$

\begin{tabular}{|c|c|c|}
\hline Empirical formula & $\mathrm{C}_{18} \mathrm{H}_{30} \mathrm{~N}_{9} \mathrm{O}_{33} \mathrm{Sm}$ & $\mathrm{C}_{18} \mathrm{H}_{26} \mathrm{~N}_{9} \mathrm{O}_{31} \mathrm{Ho}$ \\
\hline Formula weight & 1050.86 & 1029.41 \\
\hline Temperature & 293(2) K & $293(2) \mathrm{K}$ \\
\hline Wavelength & $0.71073 \AA$ & $0.71073 \AA$ \\
\hline Crystal system & Monoclinic & Triclinic \\
\hline space group & $P 2_{1} / n$ & $P-1$ \\
\hline \multirow[t]{3}{*}{ Unit cell dimensions } & $a=7.659(3) \AA \quad \alpha=90^{\circ}$ & $a=8.172(2) \AA \quad \alpha=75.12(1)^{\circ}$ \\
\hline & $b=27.534(3) \AA \beta=99.36(1)^{\circ}$ & $b=11.537(2) \AA \beta=87.06(1)^{\circ}$ \\
\hline & $c=17.824(2) \AA \quad \gamma=90^{\circ}$ & $c=20.060(2) \AA \quad \gamma=88.53(1)^{\circ}$ \\
\hline Volume & $3709(1) \AA^{3}$ & $1825.3(5) \AA^{3}$ \\
\hline Z & 4 & 2 \\
\hline Calculated density & $1.882 \mathrm{~g} / \mathrm{cm}^{3}$ & $1.873 \mathrm{~g} / \mathrm{cm}^{3}$ \\
\hline Absorption coefficient & $1.712 \mathrm{~mm}^{-1}$ & $2.291 \mathrm{~mm}^{-1}$ \\
\hline $\mathrm{F}(000)$ & 2108 & 1024 \\
\hline Crystal size & $0.40 \times 0.30 \times 0.25 \mathrm{~mm}$ & $0.84 \times 0.2 \times 0.16 \mathrm{~mm}$ \\
\hline$\theta$ range for data collection & 1.88 to $27.50^{\circ}$ & 1.83 to $25.00^{\circ}$ \\
\hline Index ranges & $-9 \leq h \leq 1,-1 \leq k \leq 35,-23 \leq l \leq 23$ & $-9 \leq h \leq 1,-13 \leq k \leq 13,-23 \leq l \leq 23$ \\
\hline Reflections collected / unique & $10806 / 8499[\mathrm{R}(\mathrm{int})=0.0448]$ & $7879 / 6399[\mathrm{R}($ int $)=0.0306]$ \\
\hline Completeness to $2(\theta)=27.50^{\circ}$ & $99.9 \%$ & $99.4 \%$ \\
\hline Refinement method & Full-matrix least-squares on $F^{2}$ & Full-matrix least-squares on $F^{2}$ \\
\hline Data / restraints / parameters & $8499 / 0 / 559$ & $6399 / 0 / 551$ \\
\hline Goodness-of-fit on $F^{2}$ & 1.043 & 1.084 \\
\hline Final $\mathrm{R}$ indices $[I>2 \sigma(I)]$ & $R_{1}=0.0583, w R_{2}=0.1297$ & $R_{1}=0.0502, w R_{2}=0.1400$ \\
\hline $\mathrm{R}$ indices (all data) & $R_{1}=0.1111, w R_{2}=0.1634$ & $R_{1}=0.0699, w R_{2}=0.1548$ \\
\hline Largest diff. peak and hole & 2.285 and $-1.656 \mathrm{eA}^{-3}$ & 2.233 and $-0.828 \mathrm{eA}^{-3}$ \\
\hline
\end{tabular}


Table 2. Selected bond lengths $[\AA]$ and angles $\left[{ }^{\circ}\right]$ for $\left[\mathrm{Sm}(\text { pic })_{2}\left(\mathrm{H}_{2} \mathrm{O}\right)_{6}\right] \cdot($ pic $) \cdot 6 \mathrm{H}_{2} \mathrm{O}$

\begin{tabular}{llll}
\hline $\mathrm{Sm}(1)-\mathrm{O}(1)$ & $2.337(5)$ & $\mathrm{O}(1)-\mathrm{C}(1)$ & $1.267(9)$ \\
$\mathrm{Sm}(1)-\mathrm{O}(8)$ & $2.385(5)$ & $\mathrm{C}(1)-\mathrm{C}(2)$ & $1.43(1)$ \\
Sm(1)-Ow7 & $2.443(5)$ & $\mathrm{C}(2)-\mathrm{N}(1)$ & $1.45(1)$ \\
Sm(1)-Ow9 & $2.461(5)$ & $\mathrm{N}(4)-\mathrm{O}(9)$ & $1.210(8)$ \\
Sm(1)-Ow10 & $2.462(5)$ & $\mathrm{N}(1)-\mathrm{O}(2)$ & $.219(9)$ \\
Sm(1)-Ow8 & $2.464(5)$ & $\mathrm{O}(8)-\mathrm{C}(7)$ & $1.254(9)$ \\
Sm(1)-Ow11 & $2.480(6)$ & $\mathrm{C}(7)-\mathrm{C}(12)$ & $1.44(1)$ \\
Sm(1)-Ow12 & $2.512(6)$ & $\mathrm{C}(7)-\mathrm{C}(8)$ & $1.44(1)$ \\
Sm(1)-O(2) & $2.773(6)$ & $\mathrm{C}(8)-\mathrm{N}(4)$ & $1.451(9)$ \\
& & & \\
Ow7-Sm(1)-Ow11 & $76.7(2)$ & $\mathrm{O}(1)-\mathrm{Sm}(1)-\mathrm{O}(2)$ & $62.3(2)$ \\
Ow9-Sm(1)-Ow11 & $73.3(2)$ & $\mathrm{O}(2)-\mathrm{N}(1)-\mathrm{C}(2)$ & $120.2(7)$ \\
Ow10-Sm(1)-Ow11 & $76.2(2)$ & $\mathrm{N}(1)-\mathrm{O}(2)-\mathrm{Sm}(1)$ & $140.4(5)$ \\
Ow8-Sm(1)-Ow11 & $130.0(2)$ & $\mathrm{O}(8)-\mathrm{C}(7)-\mathrm{C}(8)$ & $123.2(7)$ \\
O(1)-Sm(1)-Ow12 & $75.6(2)$ & $\mathrm{C}(1)-\mathrm{O}(1)-\mathrm{Sm}(1)$ & $149.8(5)$ \\
O(8)-Sm(1)-Ow12 & $70.8(2)$ & $\mathrm{O}(1)-\mathrm{C}(1)-\mathrm{C}(2)$ & $125.6(7)$ \\
Ow7-Sm(1)-Ow12 & $72.9(2)$ & $\mathrm{O}(1)-\mathrm{C}(1)-\mathrm{C}(6)$ & $121.3(7)$ \\
Ow9-Sm(1)-Ow12 & $114.8(2)$ & $\mathrm{C}(1)-\mathrm{C}(2)-\mathrm{N}(1)$ & $121.2(7)$ \\
Ow10-Sm(1)-Ow12 & $140.9(2)$ & $\mathrm{C}(7)-\mathrm{C}(8)-\mathrm{N}(4)$ & $117.6(7)$ \\
Ow8-Sm(1)-Ow12 & $68.5(2)$ & $\mathrm{O}(9)-\mathrm{N}(4)-\mathrm{O}(10)$ & $123.7(7)$ \\
Ow11-Sm(1)-Ow12 & $142.5(2)$ & $\mathrm{O}(9)-\mathrm{N}(4)-\mathrm{C}(8)$ & $119.1(7)$ \\
\hline
\end{tabular}

nitro groups is 2.773(6) $\AA$ and is quite longer than those of $\mathrm{Sm}-\mathrm{O}$ to the phenol groups in the range of 2.337(5)-2.385(5) $\AA$, indicating that one of the picrate ligands in the inner sphere coordinates to the metal ion as a so-called "quasibidentate" as found in the other picrate complexes of lighter lanthanides. ${ }^{6 a}$ This result does not agree with the study previously reported in which the picrate ligands are both unidentate in the samarium picrate. ${ }^{6 \mathrm{~d}}$

The dihedral angles between the benzene ring and its nitro groups in ortho position are good evidence for an interaction between the $\mathrm{O}$ atoms on the nitro groups and the $\mathrm{Sm}$ (III) atom. The dihedral angles were calculated to be $4.5^{\circ}$ for the coordinated nitro group and in the range $35.8^{\circ}-40.6^{\circ}$ for the uncoordinated nitro groups in ortho position, and $4.6^{\circ}-5.3^{\circ}$ for the nitro groups in the para position. The closest approach to $\mathrm{Sm}$ of the $\mathrm{O}$ atoms of the uncoordinated nitro groups is $3.75 \AA$.

The coordination polyhedron of the $\mathrm{Sm}(\mathrm{III})$ ion in $\mathbf{1}$ is shown in Figure 2.

The skeletal structure around the Sm atom forms a slightly distorted tricapped trigonal prism. The four water molecules (Ow7, Ow8, Ow10, and Ow11) and two oxygen donors (O1 and $\mathrm{O} 8$ atoms from the phenol groups) of the picrate ligand occupying the basal sites are constructed to be the trigonal prism geometry. At relatively long distances, another two water molecules (Ow9 and Ow12), and $\mathrm{O} 2$ atom from the nitro group of the chelating picrate ligand cap the sides of the trigonal prism.

The characterization and the mounting method of crystal for the data collection of Ho(III) picrate complex are similar

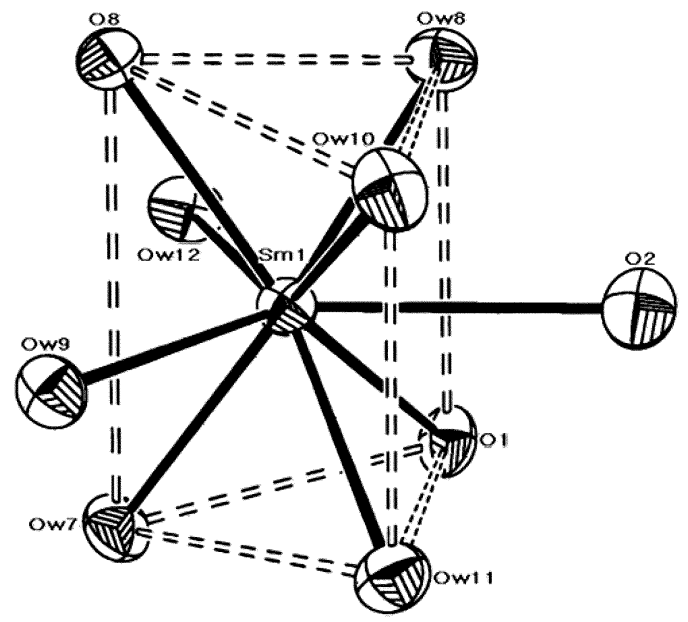

Figure 2. The coordination polyhedron of the $\mathrm{Sm}$ atom in $\left[\mathrm{Sm}(\mathrm{pic})_{2}\left(\mathrm{H}_{2} \mathrm{O}\right)_{6}\right] \cdot(\mathrm{pic}) \cdot 6 \mathrm{H}_{2} \mathrm{O}$. The tricapped trigonal prism is indicated by dashed lines.

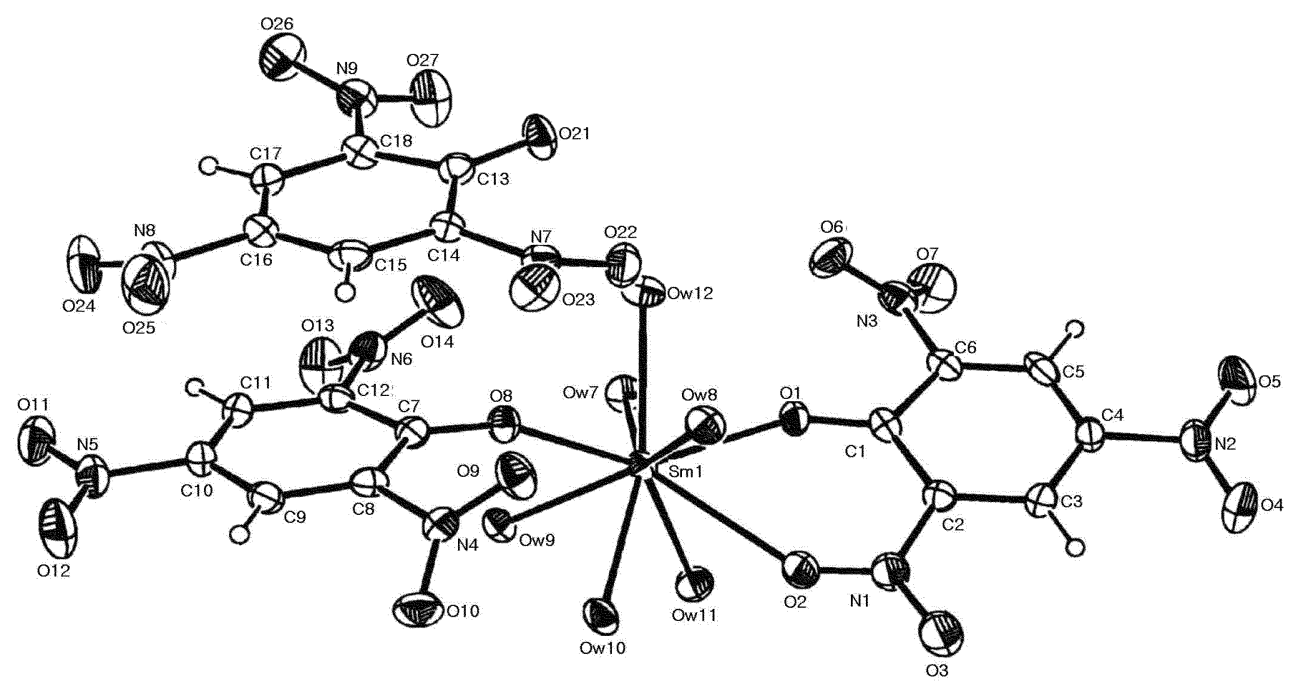

Figure 1. ORTEP diagram of $\left[\mathrm{Sm}(\text { pic })_{2}\left(\mathrm{H}_{2} \mathrm{O}\right)_{6}\right] \cdot($ pic $) \cdot 6 \mathrm{H}_{2} \mathrm{O}$ showing atom labeling. Thermal ellipsoids are drawn at the $30 \%$ probability level. 
Table 3. Selected bond lengths $[\AA]$ and angles $\left[{ }^{\circ}\right]$ for $\left[\mathrm{Ho}(\right.$ pic $\left.) \cdot 7 \mathrm{H}_{2} \mathrm{O}\right] \cdot(\text { pic })_{2} \cdot 3 \mathrm{H}_{2} \mathrm{O}$

\begin{tabular}{llll}
\hline Ho-O(1) & $2.247(5)$ & Ho-Ow10 & $2.393(7)$ \\
Ho-Ow9 & $2.348(6)$ & Ho-Ow5 & $2.397(6)$ \\
Ho-Ow8 & $2.377(6)$ & O(1)-C(1) & $1.26(1)$ \\
Ho-Ow4 & $2.381(6)$ & C(1)-C(2) & $1.42(1)$ \\
Ho-Ow7 & $2.385(6)$ & C(1)-C(6) & $1.44(1)$ \\
Ho-Ow6 & $2.388(6)$ & & \\
& & & \\
O(1)-Ho-Ow9 & $144.9(2)$ & Ow7-Ho-Ow10 & $74.3(3)$ \\
O(1)-Ho-Ow8 & $80.1(2)$ & Ow6-Ho-Ow10 & $143.5(3)$ \\
Ow9-Ho-Ow8 & $77.6(3)$ & O(1)-Ho-Ow5 & $75.2(2)$ \\
O(1)-Ho-Ow4 & $145.1(2)$ & Ow4-Ho-Ow6 & $79.5(2)$ \\
Ow9-Ho-Ow4 & $69.8(2)$ & Ow9-Ho-Ow5 & $73.2(2)$ \\
Ow8-Ho-Ow4 & $115.1(2)$ & Ow8-Ho-Ow5 & $75.5(2)$ \\
O(1)-Ho-Ow7 & $76.1(2)$ & Ow4-Ho-Ow5 & $137.4(2)$ \\
Ow7-Ho-Ow6 & $74.8(2)$ & Ow7-Ho-Ow5 & $126.7(2)$ \\
O(1)-Ho-Ow10 & $83.3(3)$ & Ow6-Ho-Ow5 & $72.3(2)$ \\
Ow9-Ho-Ow10 & $114.3(3)$ & Ow10-Ho-Ow5 & $143.4(2)$ \\
Ow8-Ho-Ow10 & $71.7(3)$ & C(1)-O(1)-Ho & $145.7(6)$ \\
Ow4-Ho-Ow10 & $73.3(3)$ & & \\
\hline
\end{tabular}

to those of $\mathrm{Sm}$ (III) picrate complex. The details of the crystallographic data for $\left[\mathrm{Ho}(\mathrm{pic})\left(\mathrm{H}_{2} \mathrm{O}\right)_{7}\right] \cdot(\mathrm{pic})_{2} \cdot 3 \mathrm{H}_{2} \mathrm{O}, 2$ are given in Table 1.

The results are very similar to those of other members of the heavier lanthanide. ${ }^{6 \mathrm{~b}}$ The stoichiometry consists of a complex cation $\left[\mathrm{Ho}(\text { pic })\left(\mathrm{H}_{2} \mathrm{O}\right)_{7}\right]^{2+}$ and a pair of picrate counter anions and three water molecules in the outer coordination sphere. It would be, because of the dehydration ability of the complexes, that the hydration number 10 of the holmium picrate is somewhat smaller than 11.5 hydrates of other picrates of the series. However, the stoichiometry of the inner sphere complex cation consists with those of the other members of heavier lanthanide. ${ }^{6}$
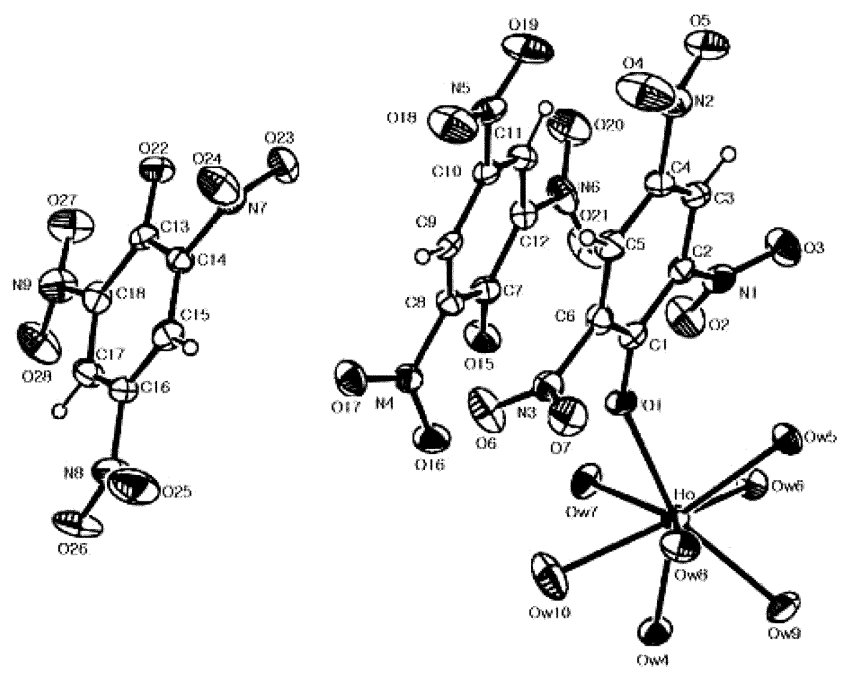

Figure 3. ORTEP diagram of $\left[\mathrm{Ho}(\right.$ pic $\left.)\left(\mathrm{H}_{2} \mathrm{O}\right)_{7}\right] \cdot(\text { pic })_{2} \cdot 3 \mathrm{H}_{2} \mathrm{O}$ showing atom labeling. Thermal ellipsoids are drawn at the $30 \%$ probability level.
The selected bond lengths and angles for complex 2 are listed in Tables 3. An ORTEP diagram of the molecular structure for complex $\mathbf{2}$ is presented by labeling atoms in Figure 3. The structural feature of complex 2 shows that the $\mathrm{Ho}$ (III) ion is coordinated to eight $\mathrm{O}$ atoms. Seven of these neighbors are the $\mathrm{O}$ atoms of water molecules (Ow4-Ow10). The Ho-O (O in water) distances are within the range of 2.348(6)-2.397(6) $\AA$ and are shorter than the sum of the covalent radii of the Ho and $\mathrm{O}$ atoms $(2.40 \AA)$. The picrate ligand coordinates to $\mathrm{Ho}$ (III) ion as a monodentate. The Ho-O atoms distances to the nitro groups in ortho position are in the range of 3.62-4.41 $\AA$, and are considerably longer than those of Ho-O atoms to the phenol groups. The Ho-O distance to the phenol group is $2.247 \AA$.

The calculated dihedral angles between the benzene rings and the nitro groups are good evidence for that there is no interaction between the $\mathrm{O}$ atoms of the nitro groups and the Ho atom. The dihedral angles are calculated to be $7.6^{\circ}$ for the nitro group in para position and in the range $34.0^{\circ}-57.9^{\circ}$ for the nitro groups in ortho position. The closest approach to Ho of the $\mathrm{O}$ atoms of the uncoordinated nitro groups is longer than $3.5 \AA$.

Figure 4 shows the coordination geometry of the Ho(III) ion. The skeletal structure around the Ho atom forms a distorted bicapped trigonal prism. A picrate ligand (O1 atom from the phenol group) and five water molecules (Ow4, Ow6, Ow8, Ow9, and Ow10) coordinated to the Ho(III) atom are constructed to be a trigonal prism geometry occupying the basal sites. Two O atoms (Ow7 and Ow5) of the water molecules coordinated to Ho(III) atom cap the sides of the distorted trigonal prism at relatively long distances.

There are hydrogen bonds between three water molecules and the $\mathrm{O}$ atoms of the picric acid ligands. The hydrogen bond length ranges from $2.80(1) \AA$ [Ow1-Hw1A $\cdots$ Ow $3^{\# 1}$ ] to 3.11(1) $\AA$ [Ow2-Hw2A $\cdots \mathrm{O} 3]$. This means that the coherence of the hydrogen bond is weakened as the hydrogen bond length is increased.

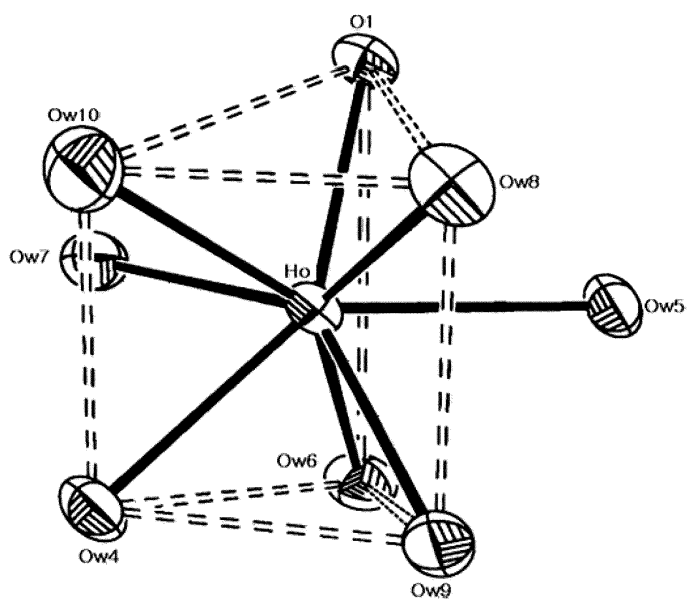

Figure 4. The coordination polyhedron of the Ho atom in $\left[\mathrm{Ho}(\mathrm{pic})\left(\mathrm{H}_{2} \mathrm{O}\right)_{7}\right] \cdot(\mathrm{pic})_{2} \cdot 3 \mathrm{H}_{2} \mathrm{O}$. The bicapped trigonal prism is indicated by dashed lines. 
Thermal analyses. TGA and DSC curves for the picric acid show that the thermal decomposition of the compound occurs in four stages from $30^{\circ} \mathrm{C}$ to $600{ }^{\circ} \mathrm{C}$. The first stage is an endothermic process, the second stage is a minor acute exothermic process, the closely following next stage is a sharp exothermic process, and the fourth is a broad exothermic process. The DSC curve is basically similar to the DTA curve previously reported, beside that the fourth exothermic peak does not appear on the DTA curve. ${ }^{16}$ The DTA curve was obtained in the temperature range only up to ca. $3500^{\circ} \mathrm{C} .{ }^{16}$

On the other hand, the TGA curve indicates that there are two mass losses between $150{ }^{\circ} \mathrm{C}$ and $600{ }^{\circ} \mathrm{C}$, the rapid mass loss to $320{ }^{\circ} \mathrm{C}$ followed by slower mass loss to $600{ }^{\circ} \mathrm{C}$. It appears that the sample of picric acid is decomposed almost perfectly with the mass loss of $98.2 \%$. The oxidation of carbon formed during the decomposition would occur in the step of slower mass loss beginning at about $320{ }^{\circ} \mathrm{C}$ which corresponds well to the fourth stage of a slow exothermic process appeared on the DSC curve.

The thermal decomposition reaction of $\left[\mathrm{Ln}(\mathrm{pic})_{2}\left(\mathrm{H}_{2} \mathrm{O}\right)_{6}\right]$. (pic) $6 \mathrm{H}_{2} \mathrm{O}(\mathrm{Ln}=\mathrm{Nd}, \mathrm{Sm}$, and $\mathrm{Gd})$ would proceed through three stages under our experimental conditions, which are the dehydration, the ring breaking of the picrate, and the formation of metal oxide. The results of thermal analysis study for the picrate complexes of neodymium, samarium, and gadolinium are almost identical to each other. Thus, the results obtained for the samarium complex $\mathbf{1}$ are discussed here representatively.

The typical thermograms of TG-DTG and DSC obtained under the conditions of linear temperature increase are shown in Figures 5 and 6 for the samarium picrate 1, respectively. TG-DTG curves indicate that the dehydration step involves the mass loss for the coordinated water molecules in the temperature range from $30{ }^{\circ} \mathrm{C}$ to $200{ }^{\circ} \mathrm{C}$. In the process of dehydration for $\mathrm{Sm}(\text { pic })_{3} \cdot 6 \mathrm{H}_{2} \mathrm{O}$ to $\mathrm{Sm}$ (pic) $)_{3}$, the observed mass loss value of $11.0 \%$ is in good agreement with the calculated mass loss value of $11.5 \%$. In fact, it is very difficult to distinguish the dehydration range from the graphic data.

The decomposition of $\mathrm{Sm}(\mathrm{pic})_{3}$ to $\mathrm{Sm}_{2} \mathrm{O}_{3}$ through the explosion of the picrate occurs from $260{ }^{\circ} \mathrm{C}$ to $593{ }^{\circ} \mathrm{C}$ with

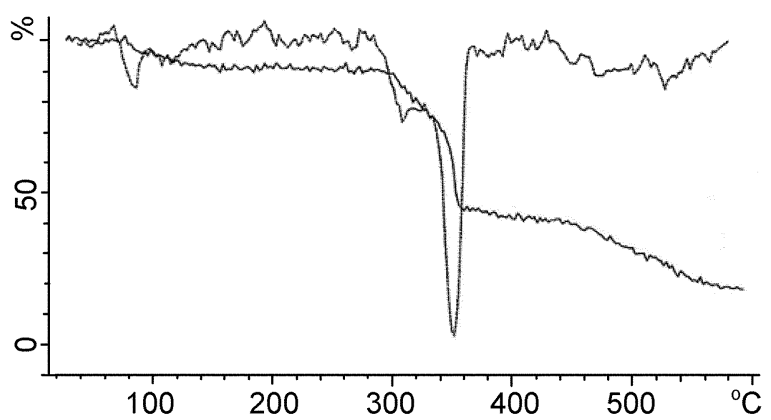

Figure 5. TG-DTG curves of $\left[\mathrm{Sm}(\mathrm{Pic})_{2}\left(\mathrm{H}_{2} \mathrm{O}\right)_{6}\right] \cdot(\mathrm{Pic}) \cdot 6 \mathrm{H}_{2} \mathrm{O}$ Sample weight: $0.891 \mathrm{mg}$, atmosphere: nitrogen gas $(20 \mathrm{~mL} / \mathrm{min}$, purity: $99.5 \%$ ).

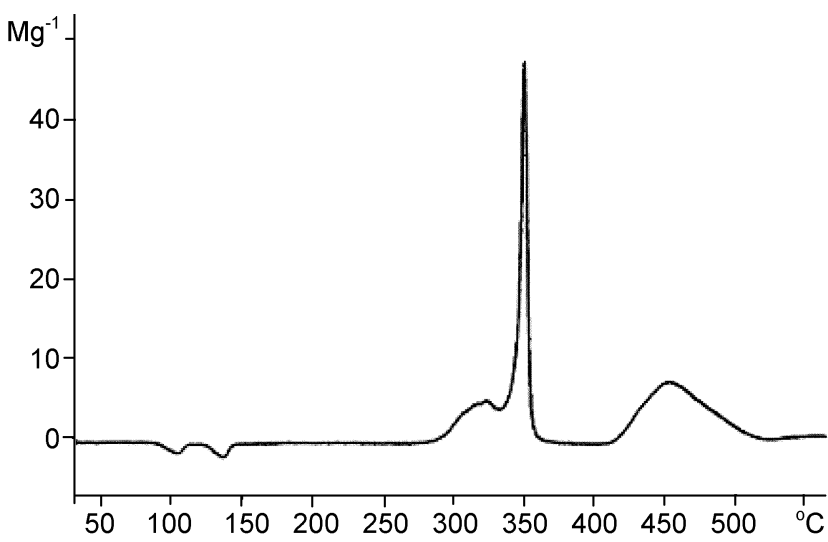

Figure 6. DSC curve of $\left[\mathrm{Sm}(\mathrm{Pic})_{2}\left(\mathrm{H}_{2} \mathrm{O}\right)_{6}\right] \cdot(\mathrm{Pic}) \cdot 6 \mathrm{H}_{2} \mathrm{O}$. Sample weight: $0.751 \mathrm{mg}$, reference sample: indium $\left(156.6{ }^{\circ} \mathrm{C}\right)$, atmosphere: static air.

the distinguished intermediate state around $400{ }^{\circ} \mathrm{C}$. The final stage would be the metal oxide formation of $\mathrm{Sm}_{2} \mathrm{O}_{3}$ from the intermediate in the temperature range of $323{ }^{\circ} \mathrm{C}-593{ }^{\circ} \mathrm{C}$. The observed mass loss value of $70.7 \%$ is in excellent agreement with the calculated value of $70.1 \%$ in this decomposition stage of $\mathrm{Sm}(\text { pic })_{3}$ to $\mathrm{Sm}_{2} \mathrm{O}_{3}$. At present it could not be suggested what the intermediate would be. However, the pattern and decomposition temperature ranges of the TGA curve are very similar to those for the lanthanide-NTO (NTO $=3$-nitro-1,2,4-triazol-5-one). It was suggested that $\mathrm{Ln}(\mathrm{NTO})_{3}$ decomposes thermally to $\mathrm{Ln}_{2}\left(\mathrm{CO}_{3}\right)_{3}$ from $180^{\circ} \mathrm{C}$ to $380{ }^{\circ} \mathrm{C}$ and then to $\mathrm{Ln}_{2} \mathrm{O}_{3}$ from $380{ }^{\circ} \mathrm{C}$ to $600{ }^{\circ} \mathrm{C}$. ${ }^{17} \mathrm{Thus}$, the decomposition mechanism of $\left[\mathrm{Ln}(\mathrm{pic})_{2}\left(\mathrm{H}_{2} \mathrm{O}\right)_{6}\right] \cdot$ (pic). $6 \mathrm{H}_{2} \mathrm{O}(\mathrm{Ln}=\mathrm{Nd}, \mathrm{Sm}$, and $\mathrm{Gd})$ would be summarized as:

$$
\mathrm{Ln}(\mathrm{Pic})_{3} \stackrel{260^{\circ} \mathrm{C}-323^{\circ} \mathrm{C}}{\longrightarrow} \text { intermediate } \stackrel{323^{\circ} \mathrm{C}-593^{\circ} \mathrm{C}}{\longrightarrow} \mathrm{Ln}_{2} \mathrm{O}_{3}
$$

DSC curve for the complexes shows that there are two small endothermic peaks between $50{ }^{\circ} \mathrm{C}-200{ }^{\circ} \mathrm{C}$ and three exothermic peaks between $260{ }^{\circ} \mathrm{C}-560{ }^{\circ} \mathrm{C}$. The two endothermic peaks would be corresponding to the dehydrations from the outer and inner spheres. The three exothermic peaks would be for the decomposition process of $\mathrm{Sm}(\mathrm{pic})_{3}$ to $\mathrm{Sm}_{2} \mathrm{O}_{3}$. A slow exothermic process begins at $279.6{ }^{\circ} \mathrm{C}$, slowly reaches its peak at $321.8{ }^{\circ} \mathrm{C}$, and quickly ends at $331.7^{\circ} \mathrm{C}$. It takes the place continuously as an exothermic process from $331.7^{\circ} \mathrm{C}$ to $373.4{ }^{\circ} \mathrm{C}$, with a sharp maximum peak at $349.0{ }^{\circ} \mathrm{C}$. The last is a slow exothermic process. It occurs from $411.1{ }^{\circ} \mathrm{C}$ to $519.8{ }^{\circ} \mathrm{C}$, with a maximum peak at $452.8^{\circ} \mathrm{C}$.

The TG-DTG and DSC curves of $\left[\mathrm{Ho}(\mathrm{pic})\left(\mathrm{H}_{2} \mathrm{O}\right)_{7}\right] \cdot(\text { pic })_{2}$. $3 \mathrm{H}_{2} \mathrm{O}, 2$ of which holmium ion is a family of the heavier lanthanides, were obtained under the conditions of linear temperature increase. The TG-DTG curves of complex $\mathbf{2}$ are basically same as those of complex 1 . The thermal decomposition processes of $\mathbf{2}$ could be divided into three steps under our experimental conditions: the dehydration, the ring breaking of the picrate, and the formation of metal oxide. 
TG-DTG curves show that the first stage of thermal decomposition of complex $\mathbf{2}$ is connected with their dehydration processes in the temperature range from $30{ }^{\circ} \mathrm{C}$ to $195{ }^{\circ} \mathrm{C}$. The dehydration stage involves mass loss for the seven coordinated water molecules in the temperature ranges from $30{ }^{\circ} \mathrm{C}$ to $195{ }^{\circ} \mathrm{C}$. In fact, it was very difficult to distinguish between the dehydration steps for inner and outer spheres from the graphic data. However, the total observed mass loss value of $17.0 \%$ is in good agreement with the total calculated mass loss value of $17.5 \%$ in the processes of dehydration.

The observed mass loss value of $63.2 \%$ at the stage from $195{ }^{\circ} \mathrm{C}$ to $584{ }^{\circ} \mathrm{C}$ is in good agreement with the calculated one of $64.1 \%$ in the decomposition of $\mathrm{Ho}(\text { pic })_{3}$ to $\mathrm{Ho}_{2} \mathrm{O}_{3}$. In this stage, a distinguished intermediate state around $380{ }^{\circ} \mathrm{C}$ is also appeared as with the case of the samarium picrate. The final mass loss from $380{ }^{\circ} \mathrm{C}$ to $584{ }^{\circ} \mathrm{C}$ is the stage of the formation of metal oxide. The decomposition mechanism of complex 2 would be summarized as same as that of complex 1 .

DSC curve of complex 2 is basically same as that of complex 1. DSC curve of complex 2 shows the thermal decomposition reaction of the holmium picrate complex consists of five stages from $30{ }^{\circ} \mathrm{C}$ to $600{ }^{\circ} \mathrm{C}$. The first two stages are endothermic processes for the dehydration from the complex. The third stage is a minor acute exothermic process, the closely following fourth stage is a sharp exothermic process, and the fifth is an acute exothermic process, all for the decomposition of $\mathrm{Ho}(\mathrm{Pic})_{3}$ to $\mathrm{Ho}_{2} \mathrm{O}_{3}$.

Supplementary Material. Complete lists with atomic coordinates, anisotropic displacement parameters, bond lengths and angles have been deposited at the Cambridge Crystallographic Data Center, 912 Union Road, Cambridge CB2 1EZ, UK [CCDC 236996 for Ho complex and CCDC 236997 for Sm complex].
Acknowledgements. This work was supported by a grant No. R01-2001-00055 from Korea Science and Engineering Foundation and a grant from Chungnam National University.

\section{References}

1. Stammler, M. Therm. Anal., Proc. Int. Conf., 2nd.; Schwenker, R. F. Jr., Ed.; Academic Press: New York, N.Y., 1969; Vol. 2, pp 1127-1146.

2. Nakagawa, K.; Amita, K.; Mizuno, H.; Inoue, Y.; Hakushi, T. Bull. Chem. Soc. Jpn. 1987, 60, 2037.

3. Brill, T. B.; Zhang, T. L.; Tappan, B. C. Combust. Flame 2000, 121, 662 .

4. Iwasaki, F.; Sato, M.; Aihara, A. Acta Cryst. 1976, B32, 102.

5. Zanin, I. E.; Antipin, M. Y.; Simonov, Y. A.; Yampol'skaya, M. A.; Struchkov, Y. T. Sov. Phys. Crystallogr. 1992, 37, 640.

6. (a) Harrowfield, J. M.; Lu, W.; Skelton, B. W.; White, A. H. Aust. J. Chem. 1994, 47, 321. (b) Harrowfield, J. M.; Lu, W.; Skelton, B. W.; White, A. H. Aust. J. Chem. 1994, 47, 339. (c) Harrowfield, J. M.; Lu, W.; Skelton, B. W.; White, A. H. Aust. J. Chem. 1994, 47, 349. (d) Harrowfield, J. M.; Skelton, B. W.; White, A. H. Aust. J. Chem. 1994, 47, 359.

7. Suh, H. R.; Suh, H. S.; Yun, S. S.; Lee, E. K.; Kang, S. K. Acta Cryst. 2002, C58, m202.

8. Suh, H. R.; Suh, H. S.; Yun, S. S.; Lee, E. K.; Kang, S. K. Acta Cryst. 2002, E58, m284.

9. Kimura, K.; Maeda, T.; Shono, T. Talanta 1979, 26, 945.

10. Maeda, T.; Kimura, K.; Shono, T. Bull. Chem. Soc. Jpn. 1982, 55, 3506.

11. Layton, A. J.; Nyholm, R. S.; Banerjee, A. K.; Fenton, D. E.; Lestas, C. N.; Truter, M. R. J. Chem. Soc. (A) 1970, 1894.

12. Nakagawa, K.; Amita, K.; Mizuno, H.; Inoue, Y.; Hakushi, T. Bull. Chem. Soc. Jpn. 1987, 60, 2037.

13. Melo, W. C.; Zain, M.; Matos, J. R.; Isolani, P. C.; Zinner, K.; Zinner, L. B. J. Alloys Comp. 1995, 225, 344.

14. Sheldrick, G. M. SHELXS97 and SHELXL97, Program for the Refinement of Crystal Structures; University of Göttingen: Germany, 1997.

15. Farrugia, L. J. J. Appl. Cryst. 1997, 30, 565.

16. Hara, Y.; Eda, H.; Osada, H. Kokyo Kayaku 1975, 36, 66.

17. Xie, R.; Hu, R.; Zhang, T.; Li, F. J. Therm. Anal. 1993, 29, 41. 